\title{
Nanocrystalline Structure of Metal Containing Films in Natural Wetlands
}

\author{
P. Plachinda*, R. W. Smith*, S. Rouvimov*, E. J. Sánchez*, P. Moeck*, R. Hugo**, and C. \\ Wang***
}

* Department of Physics, Portland State University (PSU), Portland, Oregon 97207-0751

** Department of Geology, Portland State University, Portland, Oregon 97207-0751

*** Pacific Northwest National Laboratory (PNNL), Richland, Washington 99352

Recent progress in transmission electron microscopy (TEM) instrumentation allows for structural and chemical analysis in geo-, environmental and geomicrobiological sciences at atomic and nanoscale levels. We demonstrate this TEM capability in application to transition metal containing substances resulted from the activities of "iron bacteria", as their sole energy source. The substance, often appeared as silvery, water-surface film, is common for natural wetlands, ephemeral pools, springs and seeps with metalliferous sediments and weathered rocks [1]. Depending on the type of bacteria, concentration of organic material and dissolved oxygen in the water, bacteria may either reduce insoluble ferric oxide $\left(\mathrm{Fe}^{3+}\right)$ in aquifer soils to soluble ferrous hydroxide $\left(\mathrm{Fe}^{2+}\right)$ or convert soluble ferrous iron $\left(\mathrm{Fe}^{2+}\right)$ into ferric oxide. Thus, the valence state of the metals in the films allows for the elucidation of biogeochemical processes at the air-water interface and in the water.

The samples were collected at natural resources in Oregon and prepared as described in [2]. Electron Energy Loss Spectroscopy (EELS) was employed to determine the valence state of transition metal ions [3]. The structural and chemical analysis of the samples has been performed by both FEI Tecnai $\mathrm{G}^{2}$ ST field-emission and $\mathrm{LaB}_{6}$ JEOL JEM 2010 electron microscopes (both equipped with EELS and EDXS) at PSU and PNNL, respectively.

A typical TEM bright field image and the corresponding selected area electron diffraction (SAED) pattern are shown in Fig. 1. In agreement with previous observations (e.g. Grathoff et al. [1]), the films appear rather amorphous in SAED patterns (Fig. 1). However, TEM images of the same area at higher magnifications/resolutions (Figs. 2 and 3) show that the films consist of nano-crystallites of about 2-5 $\mathrm{nm}$ in size. This suggests that some products of bacteria activity may be nano-crystallites rather than amorphous. Energy Dispersive X-ray Spectroscopy (EDXS) indicates that the samples contain a mixture of iron and manganese oxides, organic material and traces of other elements (Fig. 4). The EELS spectra of the samples (Fig. 5) reveal the transition metal "white lines" features, i.e. $\mathrm{L}_{2,3}$ edges. These $\mathrm{L}_{2,3}$ features correspond to transitions from the $2 \mathrm{p}_{1 / 2}$ and $2 \mathrm{p}_{3 / 2}$ states to unoccupied $3 \mathrm{~d}_{3 / 2}$ and $3 \mathrm{~d}_{5 / 2}$ states and are widely used for the estimation of valences of $3 \mathrm{~d}$ transition metals [3]. After subtraction of the background and integration of the area underneath both EELS peaks within a $4 \mathrm{eV}$ window, the ratio between the " $\mathrm{L}_{2,3}$ areas" yields the actual valence state. In the case of iron, this ratio was $5.2 \pm 0.3$ and close to the value obtained for a Magnetite reference sample in which the iron oxidation state is $\mathrm{Fe}^{+2.66}$. The ratio between the $\mathrm{L}_{2,3}$ areas was for manganese $3.4 \pm 0.5$. This is between the tabulated ratios for $\mathrm{Mn}^{2+}=4.3$ and $\mathrm{Mn}^{3+}=2.3[4]$ and gives the average oxidation state of manganese as $\mathrm{Mn}^{+2.45}$. The EELS results confirm the mixed valences of metal ions as suggested earlier (e.g. Grathoff et al. [1]) and indicate on incomplete oxidation process [5].

References

[1] C. S. Cockell, Phil Trans R Soc A 369 (2011) 516; M. Blothe and E. E. Roden, Appl. Environ. Microbiol. 75 (2009) 468; G. H. Grathoff et al., Clays and Clay Minerals 55 (2007) 635; K. J. Edwards et al. Appl. Environ. Microbiol. 69 (2003) 2906. 
[2] R. W. Smith and J. Dash, Proceedings of Microsc. Microanal. Meeting, (1989) 1004.

[3] T. G. Sparrow et al., Chem. Phys. Lett. 108 (1984) 547.

[4] K.-F. Chen, et al, Micron 38 (2007) 354.

[5] This research was supported by the Oregon Nanoscience and Microtechnologies Institute. The research at the PNNL by one of the authors (P. Plachinda) was supported by the NSF-CRC grant (P.I.: Prof. Daniel R. Gamelin, University of Washington).

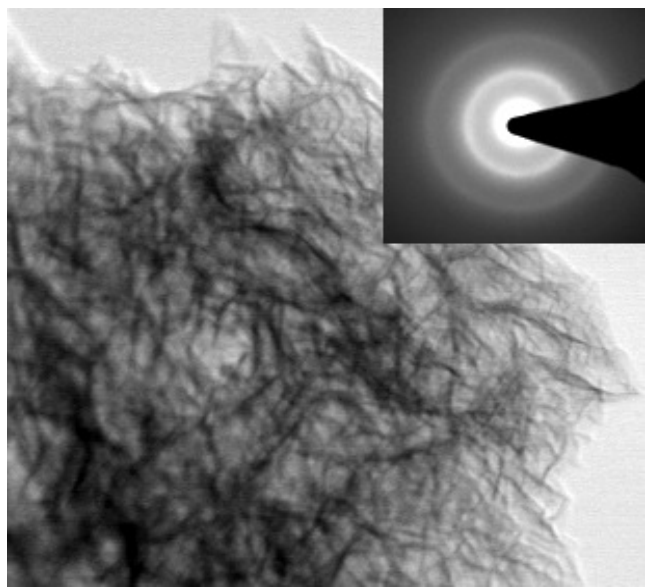

FIG. 1. Typical TEM bright-field image of naturally occurring thin floating films with SAED pattern as inset. Note the "fibrous-like" structure of the film.

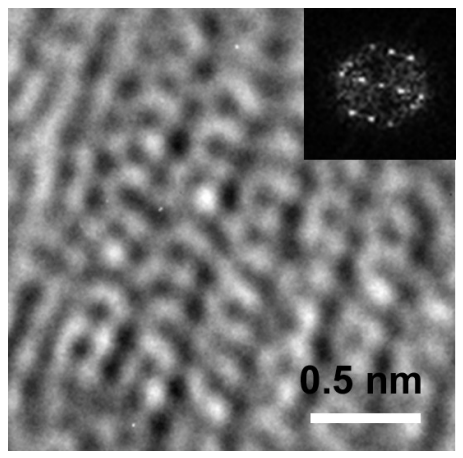

FIG. 3. A selected region of the HRTEM image of Fig. 2 with the amplitude part of its Fourier transform as inset.

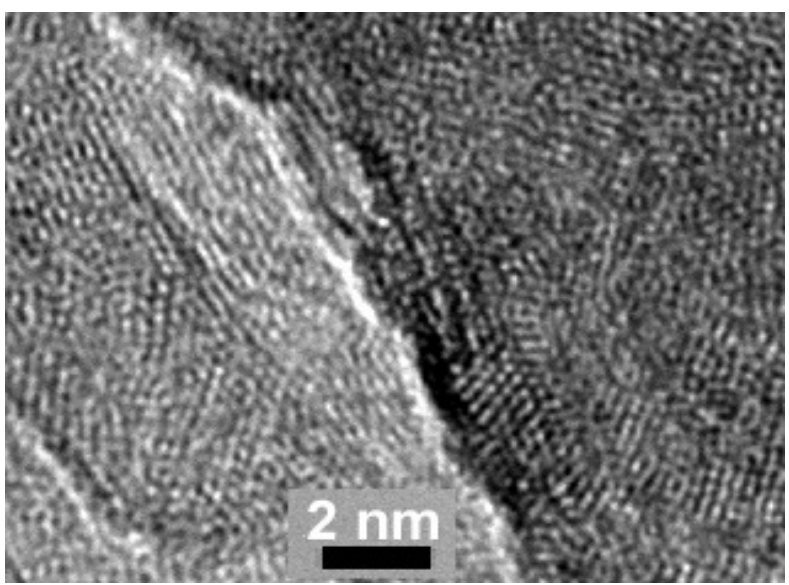

FIG 2. HRTEM image of the same sample, recorded near the edge of the film shown in Fig. 1. The size of nano-crystallites ranges from approximately 2 to $5 \mathrm{~nm}$.

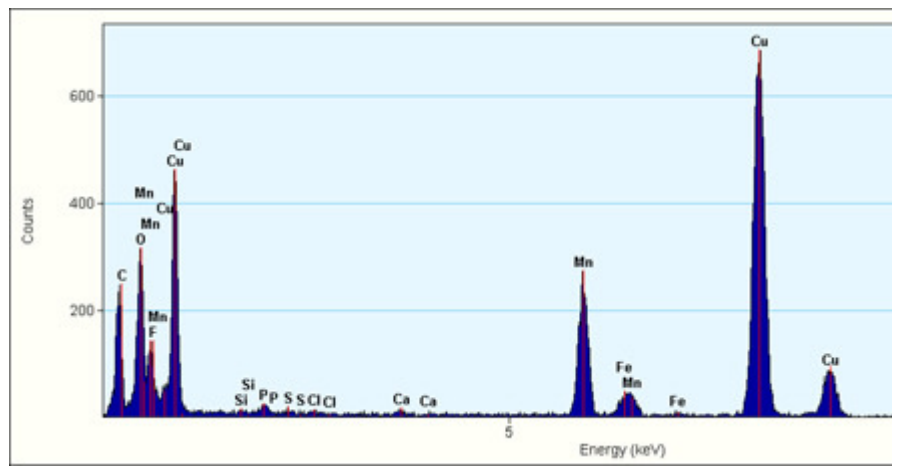

FIG. 4. EDXS data corresponding to the sample area shown in Fig. 1. The presence of copper peaks is most likely due to the TEM grid.
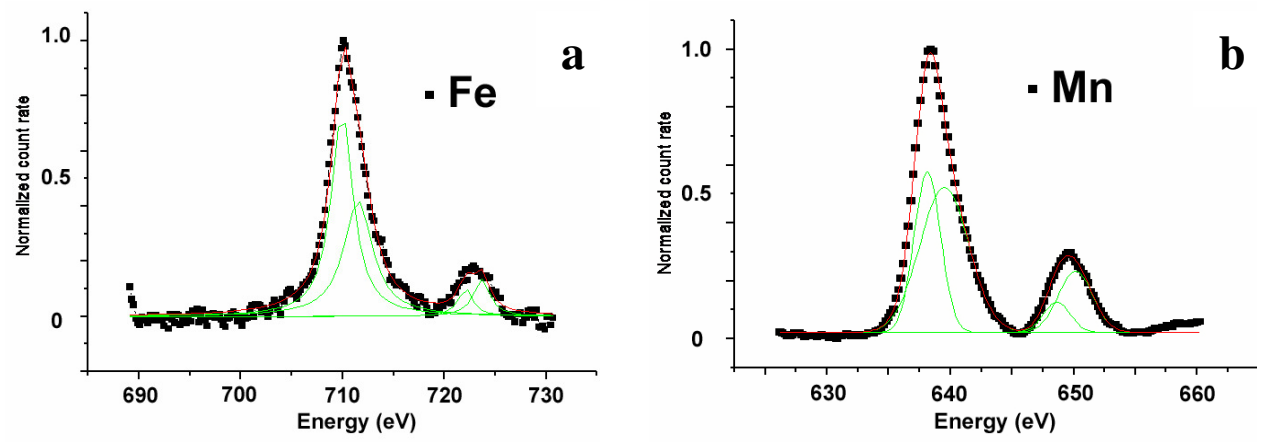

FIG. 5. EELS data from the same sample for $\mathrm{Fe}$ (a) and $\mathrm{Mn}$ (b) $\mathrm{L}_{2,3}$ edges. 